\title{
Bridging science and conscience (or growing up on research ethics!)
}

\author{
Abhinav Vaidya, MD \\ Associate Professor, \\ Department of Community Medicine, Kathmandu Medical \\ College Teaching Hospital, Kathmandu, Nepal.
}

I cannot be overemphasized that ethical consideration is at the centre of research. The overarching principles of ethics cover both 'science' aspects of a research such as methodological issues and 'conscience' aspects, for example, evaluation of risks to the participants. For various reasons, however, the core ethical considerations often take a backseat and the methodological aspects get more emphases. In this informal write-up, I look back into the research works that I was involved in the last twelve years and reflect on their ethical aspects. I contemplate on whether I could have done things in a different way, or rather, in a more ethical manner. By doing so, I intend to bring forth some of the ethics-related issues that we come across during research, that we tend to overlook, especially as young researchers. This is, of course, not a comprehensive list of ethical issues in health research, but only a few of them.

After my graduation in medical science at the turn of the millennium, I began working in a cardiology-centric private hospital in Nepal. A rare research opportunity fell into my lap during that period- to implement the international Interheart study in the hospital. Interheart was a case-control study on risk factors associated with myocardial infarction ${ }^{1}$. As the research officer, I was mostly ensuring that the medical officers involved in the study were collecting data in a methodologically sound manner. The ethical issues, I must admit, did not cross my mind at all. While the national-level coordinator must have had undergone all the pre-requisites such as obtaining ethical approval from the Nepal Health Research Council (e.g., for transfer of blood samples to Canada) I was not bothered about such ethical aspects at all. Further, one of the challenges of the study was to find matching controls. We tried two strategies to solve the problem- one, the medical officers brought their relatives, and two, we offered free electrocardiogram, echocardiogram and blood tests for sugar and lipids to those who consented to participate. On hindsight, these strategies raise the ethical issue of respondents participating due to cannot-say-no pressure (relatives) or lucrative offer (diagnostic incentives).

I later moved on to community-based research in cardiovascular health, and my MD thesis involved study of coronary heart disease in an Eastern Nepalese town where my medical institute was situated. Besides the Rose angina questionnaire that elicited information about history of chest pain, I was going to use electrocardiographic measurements to determine if the person had coronary heart disease or not. Only male participants were to be enrolled in my study because everyone thought that it would be socially difficult to do electrocardiography in women in the community. The institutional review board also approved my proposal without discussing much on this gender issue. This study, done in 2004-5, happens to be the only community-based study so far that looked at the prevalence of coronary heart disease in $\mathrm{Nepal}^{2}$. It was only afterwards that I realized that women also equally deserved to be included in the study, and that I should have probably instead tried to find ways to include them as well. Another ethical error that I can recall committing during this study was regarding the confidentiality of the respondents, which is in fact a major problem in community-based studies especially where the households are not discrete. Many a times, I interviewed them in their porch surrounded by the curious eyes and ears of the neighbours. Ideally, for the sake of privacy, I should have asked the respondents for the possibility of the interview indoors, or should have persuaded the neighbours to not to crowd themselves around the respondent.

Moving on, during my early years as a lecturer at my current institute, I had published an article based on a community diagnosis program that our department 
had conducted ${ }^{3}$. Being an academic activity of the undergraduate students and a part of the curriculum, we did not take ethical clearance from the ethical board of the institute, nor did we pay heed to the consent of the respondents. This is in fact a common practice- in both clinical and basic science - but how correct is the practice? If academic exercise was the purpose, was it alright to publish the data in the form of a scientific paper? Realising that this was not an ethical practice, even though the premise is an academic one, when we recently studied non-communicable diseases in a nearby slum, we made sure that we obtained institutional ethical clearance as well as consent from the respondents ${ }^{4}$.

Another ethical negligence is the dissemination of the research findings to the local community. Once data collection is completed, dissemination part to the community from where the data came is often forgotten or neglected. At the most, the findings are shared with the local authority or the local leaders. Here I mention an example of dissemination of the findings to the entire community may be done. We have established a health-demographic surveillance site in two villages of Bhaktapur district where we do a census every two years. It usually takes a year for data entry and analysis to be completed ${ }^{5}$. The challenge then lies in disseminating the findings to the entire community of some three thousand households. So, what we did was that when the enumerators visited the households again for the next round of survey, at the end of the interview, they gave the respondents a one-page summary of the previous round's findings translated in Nepali language. This ensured that the results were disseminated to each and every household and without additional manpower cost.

Finally, ethical overstepping is a common practice in research publication. As an editor of a journal, we come across many submissions of dubious nature. One

\section{REFERENCES}

1. Yusuf $S$, Hawken $S$, Ôunpuu $S$, Dans $T$, Avezum A, Lanas F, et al. INTERHEART Study Investigators. Effect of potentially modifiable risk factors associated with myocardial infarction in 52 countries (the INTERHEART study): case-control study. Lancet. 2004;364(9438):937-52.

2. Vaidya A, Pokharel PK, Nagesh S, Karki P, Kumar particular example is of a manuscript that was submitted to the journal and one of the editorial assistants found out that the paper had already been published in another journal albeit with the data collection date shifted backward by about six months in the published version. Apparently, the article had been submitted to us even when it had been already submitted to another journal, and had even been published there. The editorial board obviously decided not to publish the article.

These are but some of the ethical issues that we have to bear in mind while doing research. Clearly, there are many more aspects of research ethics that are equally important at the different stages of research: informed consent, potential harm and possible benefits to the participants, conflicts of interest, and so on. I would recommend some good reading materials like Paul Oliver's book for an overview of important considerations on ethics for a student's perspective ${ }^{6}$; the latest version of Declaration of Helsinki ${ }^{7}$ published by World Medical Association for the ethical principles involving human subjects; the ethical guidelines ${ }^{8}$ issued by Nepal Health Research Council for conducting any research in Nepal. Another must read for learning publication ethics is the document 'Uniform Requirements for Manuscripts Submitted to Biomedical Journals: Writing and Editing for Biomedical Publication'9 released by the International Committee of Medical Journal Editors.

To conclude, ethical misconduct is often an act of commission but more often, it results from omission. There is a subtle borderline between ethical and unethical research behaviour. Whenever we fight that inner dilemma such as ' $K$ matlab!' (Who cares!) and 'kasle thaha paunchha ra?' (Who will find this out?), we are often likely to cross that line and fall into the misconduct trap. As health scientists, we must learn not to fall into this trap and along with science, be equally aware of a basic human trait called conscience.

S, Majhi S. Prevalence of coronary heart disease in the urban adult males of eastern Nepal: A population-based analytical cross-sectional study. Indian Heart J. 2009;61:341-47.

3. Vaidya A, Pradhan A, Joshi S, Gopalakrishnan $S$, Dudani I. Acquaintance with the actuality: community diagnosis programme of Kathmandu 
Medical College at Gundu village, Bhaktapur, Nepal. Kathmandu Univ Med J. 2008;6:128-34.

4. Oli N, Vaidya A, Thapa G. Behavioural Risk Factors of Non-communicable Diseases among Nepalese Urban Poor: a Descriptive Study from a Slum Area of Kathmandu. Epidemiol Res Int. 2013;2013:1-13.

5. Aryal UR, Vaidya A, Shakya-Vaidya S, Petzold M, Krettek A, Sinamangal N. Establishing a health demographic surveillance site in Bhaktapur district, Nepal: initial experiences and findings. BMC Research Notes. 2012;5(1):489.

6. Oliver $P$. The student's guide to research ethics. 2nd ed. Berkshire, England: McGraw-Hill International; 2010. 180p.
7. World Medical Association. World Medical Association Declaration of Helsinki: Ethical Principles for Medical Research Involving Human Subjects. JAMA. 2013;E1-4.

8. Nepal Health Research Council. National Ethical Guidelines for Health Research in Nepal and Standard Operating Procedures [Internet]. Kathmandu: Nepal Health Research Council; 2011[cited 2013 Nov 10]. Available from: http:// nhrc.org.np/guidelines.

9. González Vegas J. Uniform Requirements for Manuscripts Submitted to Biomedical Journals: Writing and Editing for Biomedical Publication. Revista Vitae 2013; 3:1-17. 